\title{
Variants of the Plasmodium vivax Circumsporozoite Protein (VK210 and VK247) in Colombian Isolates
}

\author{
JM González ${ }^{+}$, S Hurtado, M Arévalo-Herrera, S Herrera
}

Instituto de Inmunología del Valle, Universidad del Valle, Carrera 4B, No. 43-00, Cali, Colombia

Phenotypic diversity has been described in the central repeated region of the circumsporozoite protein (CSP) from Plasmodium vivax. Two sequences VK210 (common) and VK247 (variant) have been found widely distributed in $\mathrm{P}$. vivax isolates from several malaria endemic areas around the world. A third protein variant called $\mathrm{P}$. vivax-like showing a sequence similar to the simian parasite $\mathrm{P}$. simioovale has also been described. Here, using an immunofluorescent test and specific monoclonal antibodies, we assessed the presence of two of these protein variants (VK210 and VK247) in laboratory produced sporozoite. Both sequences were found in parasite isolates coming from different geographic regions of Colombia. Interestingly, sporozoites carrying the VK247 sequence were more frequently produced in Anopheles albimanus than sporozoites with the VK210 sequence. This difference in sporozoites production was statistically significant ( $p<0.05$, Kruskal-Wallis); not correlation was found with parameters as the total number of parasites or gametocytes in blood from human donors used to feed mosquitoes. Previous studies in the same region have shown a higher prevalence of anti-VK210 antibodies which in theory may suggest their role in blocking the development of sporozoites carrying the CSP VK210 sequence.

Key words: Plasmodium vivax - sporozoites - Anopheles - Colombia

The circumsporozoite protein (CSP) is the major coat protein of the malaria sporozoites. It presents a central repeat domain flanked by non-repeated amino and carboxyl sequences containing highly conserved protein stretches (regions I and II). These flanking regions also display some degree of polymorphysm (Mann et al. 1994). In Plasmodium vivax the first sequenced gene encoded a tandemly repeated nonapeptide GDRA(D/ A)GQPA that later was termed common or VK210 sequence (Arnot et al. 1985). Phenotypic heterogeneity in the repeated region of the $P$. vivax CSP was initially described in parasites isolates from Thailand expressing the nonapeptide ANGA(G/D)/ N/D)QPG, termed variant or VK247 sequence (Rosenberg et al. 1989). A third sequence from the CSP was obtained from a parasite resembling mor-

\footnotetext{
This work was supported by the Fondo Colombiano de Investigaciones Científicas y Proyectos Especiales" Francisco José de Caldas" (Colciencias).

${ }^{+}$Corresponding author. Fax: +57-1-2850503. E-mail: jmgonzal@javeriana.edu.co

Received 5 April 2000

Accepted 22 August 2000
}

phologically to $P$. vivax. The CSP repeat sequence (APGANQEGGAA) was found to be similar to the simian malaria parasite $P$. simio-ovale (Qari et al. 1993a). Serologic surveys in several $P$. vivax endemic areas demonstrated the presence of antibodies that recognize recombinant and synthetic polypeptides that represent the three CSP variants (Wirtz et al. 1990, Franke et al. 1992, Marrelli et al. 1998). Using DNA techniques (Kain et al. 1991), the VK210 and VK247 sequences were found in $P$. vivax isolates distributed worldwide (Mann et al. 1994, Sattabongkot et al. 1994). Despite the fact that this third CS sequence was found in parasite isolates around the world (Qari et al. 1993b), its global distribution was not confirmed in another study (Gopinath et al. 1994). Wild parasite isolates display a number of silent mutations throughout the whole CSP gene sequence, these mutations do not represent changes in the protein sequence (Mann et al. 1994).

Here, we report the frequence of the two CSP variants (VK210 and VK247) in wild P. vivax isolates from Colombia as determined by direct immunofluorescent test (IFAT) in laboratory produced sporozoites. We also describe the susceptibility of Anopheles mosquitoes to the experimental infection with parasites carrying one of these two CSP sequences. 
Human blood samples were obtained from 70 individuals who requested medical attention at the Malaria Eradication Service (SEM) in Cali and Buenaventura during 1994-1996. These individuals came from three different geographic regions of Colombia: Antioquia, the Eastern Savanna and the Pacific Coast (Figure). Infection by $P$. vivax parasite was diagnosed in all patients using Giemsa stained thick and thin smears. Whole blood samples were obtained by venous puncture using heparinized syringes and transported to the laboratory within $1 \mathrm{~h}$ after bleeding. Adult female An. albimanus mosquitoes from two different strains: Tecojate (Guatemala) and Buenaventura (Colombian Pacific Coast) were used to produce sporozoites. Batches of 500 mosquitoes were put in individual cages and fed using artificial membrane feeders containing the $P$. vivax infected human blood. Mosquitoes were then kept at $27^{\circ} \mathrm{C}$ and $85 \%$ of relative humidity. Infection was confirmed at day 8 after blood feeding by the observation of gut oocysts in a sample of exposed mosquitoes. Salivary glands were dissected in sterile PBS $1 \mathrm{x} \mathrm{pH}$ 7.4 at day 14 after infection and the number of sporozoites was calculated using a blood count chamber (Salas et al. 1994). Slides for IFAT were prepared using air-dried sporozoites. Two mAbs (kindly provided for R Nussenzweig, New York

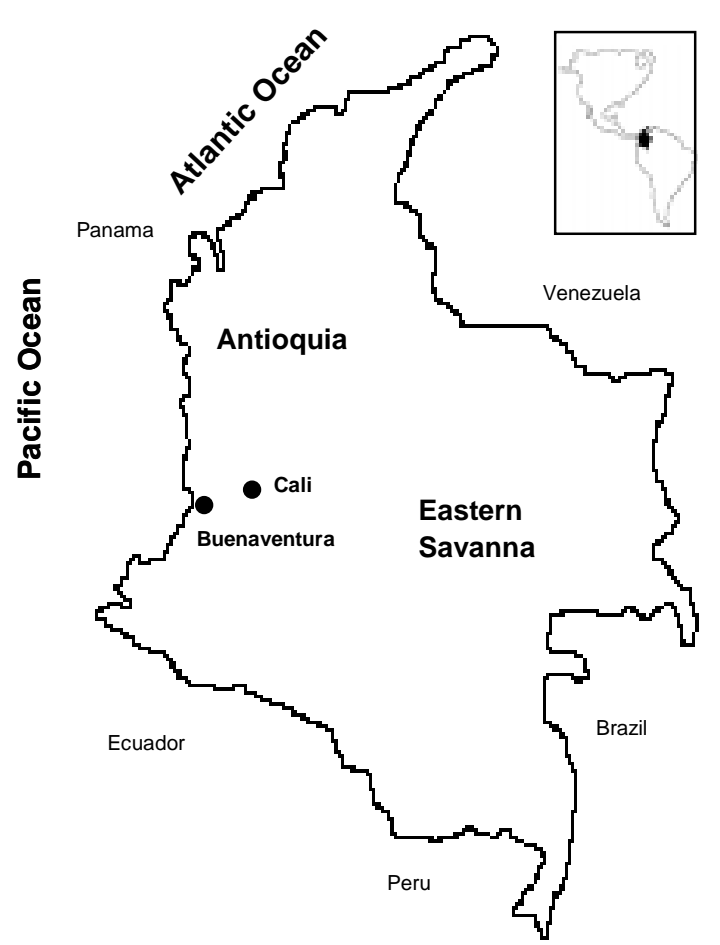

Map of Colombia showing locations where malaria isolates were obtained.
University) specific to $P$. vivax CSP were used: 2F2 and 2E10 which recognized VK210 and VK247, respectively. A third mAb 2A10 which recognized the central region of $P$. falciparum was used as a negative control. Reaction was revealed using 1/50 PBS diluted IgG anti-mouse FITC (Sigma). Evaluation was carried out by two independent readers with a fluorescent light microscope with 40x and 100x immersion oil lenses. Each isolate was tested at least twice in duplicate or triplicate spots. Information obtained was processed and analyzed using the EPINFO software.

A total of 67 P. vivax sporozoite isolates representing $96 \%$ of blood samples used for mosquito feeding were analyzed. The isolates were from The Pacific Coast region 52 (77.6\%), The Eastern Savanna region $10(14.9 \%)$ and Antioquia 5 (7.5\%); these three regions contributing yearly with $87 \%$ of the malaria cases in Colombia. IFAT showed the VK210 sequence in $22(32.8 \%)$ isolates an the VK247 sequence in $40(59.7 \%)$ isolates. Five $(7.5 \%)$ of the samples reacted with both mAbs indicating the presence of mixed infection (Table I). Most sporozoite lots (60/90\%) were produced in An. albimanus Tecojate strain and the remaining $(7 / 10 \%)$ in Buenaventura strain. All sporozoites obtained in the Buenaventura strain displayed the VK247 sequence. Five isolates containing mixed reaction were obtained in the Tecojate strain. There was a significant statistical correlation between the phenotype of the central region of the $P$. vivax CS protein and number of sporozoites obtained ( $\mathrm{p}$ $<0.05$, Kruskal-Wallis). As shown in Table II, sporozoites with VK247 were produced more abundantly than VK210. There was not statistical correlation between other variables such as total parasitaemia or gametocitaemia in the blood donors and number of sporozoites produced.

In a recent study, it was demonstrated a differential susceptibility of Anopheles mosquitoes to malaria infection with $P$. vivax isolates in Mexico. Indeed, An. albimanus and An. pseudopunctipennis were preferentially infected by VK210 and VK247 variants, respectively (González-Ceron et al. 1999). In our work, comparison of sporozoite rates between the two Anopheles strains used (Tecojate and Buenaventura) are not possible due to differences in the number of exposed batches. Naturally acquired antibodies that recognize the VK247 sequence have been demonstrated less prevalent than those recognizing VK210 in several countries: Thailand (Wirtz et al. 1990), Peru (Franke et al. 1992), Brazil and India (Cochrane et al. 1990). Malaria cases in Colombia for the period of this study (1994-1996) were predominantly due to $P$. vivax (62\%). We have previously demonstrated that anti-CSP antibodies in donors from the Colombian 
TABLE I

Geographic origin of the Plasmodium vivax isolates and distribution of circumsporozoite (CS) protein variants

\begin{tabular}{lcccr}
\hline Geographic area & VK210 & VK247 & Mixed & Total \\
\hline Antioquia & 0 & 5 & 0 & 5 \\
Pacific Coast & 18 & 31 & 3 & 52 \\
Eastern Savanna & 4 & 4 & 2 & 10 \\
\hline Total & 22 & 40 & 5 & 67 \\
\hline
\end{tabular}

$a$ : sporozoites carrying the common sequence of the $P$. vivax CS protein; $b$ : sporozoites with the variant sequence

TABLE II

Plasmodium vivax CS circumsporozoite protein (CSP) variants and sporozoites production

\begin{tabular}{lcccr}
\hline $\begin{array}{l}\text { CSP } \\
\text { variant }\end{array}$ & $\begin{array}{c}\text { No. of } \\
\text { mosquito batches }\end{array}$ & $\begin{array}{c}\text { No. of sporozoites } \\
\text { obtained }^{a}\end{array}$ & $\begin{array}{c}\text { Mean } \\
\text { sporozoites/batch }\end{array}$ & $\begin{array}{r}\text { Mean of dissected } \\
\text { mosquitoes/bath }\end{array}$ \\
\hline VK210 & 22 & $2^{\prime} 895,450$ & $131,611.3$ & 160 \\
VK247 & 40 & $14^{\prime} 691,750$ & $367,293.7$ & 184 \\
\hline Total & 62 & $17^{\prime} 587,200$ & & \\
\hline
\end{tabular}

$a$ : sporozoites with mixed reaction were not included $(\mathrm{n}=5)$.

Pacific Coast to VK210 are more frequent (68$75 \%)$ than to VK247 (11-20\%) (Arévalo-Herrera et al. 1998). However, we report here a predominance of malaria isolates carrying the VK247 sequence $(67 \%)$ when the used read-out is the sporozoite production. Putting together our data it appears as if anti-CSP antibodies against VK210, which are more prevalent in the same geographic region, could block the development of the VK210 sporozoites and therefore they become less frequent in mosquitoes. Alternatively, it might be that VK210 is more immunogenic that VK247 and that would explain that lower prevalence of VK210 sporozoites induces higher antibody prevalence. This might result in the selection of the VK247 sporozoites. It is clear that CSP is required to complete the cycle inside the mosquito (Menard et al. 1997). In contrast to this hypothesis, previous reports using $P$. falciparum showed enhancing of sporozoite production when antibodies to the central region were present in the serum (Do Rosario et al. 1989). Current experiments addressing this question are going on. These findings will allow us to continue expanding our knowledge on the behavior of $P$. vivax CSP and to understand the complex relationship between parasites, vectors and the human immune response.

\section{ACKNOWLEDGMENTS}

To M Salas, H Ortiz , JC Millán and MF Suárez for their help and technical assistance.

\section{REFERENCES}

Arévalo-Herrera M, Roggero MA, González JM, Vergara J, Corradin G, Lopez JA, Herrera S 1998.
Mapping and comparison of the B-cell epitopes recognized on the Plasmodium vivax circumsporozoite protein by immune Colombians and immunized Aotus monkeys. Ann Trop Med Parasitol 92: 539551.

Arnot DE, Barnwell JW, Tam JP, Nussenzweig V, Nussenzweig RS, Enea V 1985. Circumsporozoite protein of Plasmodium vivax: gene cloning and characterization of the immunodominant epitope. Science 230: 815-818.

Cochrane AH, Nardin EH, de Arruda M, Maracic M, Clavijo P, Collins WE, Nussenzweig RS 1990. Widespread reactivity of human sera with a variant repeat of the circumsporozoite protein of Plasmodium vivax. Am J Trop Med Hyg 43: 446-451.

Do Rosario VE, Appiah A, Vaughan JA, Hollingdale MR 1989. Plasmodium falciparum: administration of anti-sporozoite antibodies during sporogony results in production of sporozoites which are not neutralized by human anti-circumsporozoite protein vaccine sera. Trans $R$ Soc Trop Med Hyg 83: 305307.

Franke ED, Lucas CM, San Roman E, Wirtz RA 1992. Prevalence of antibody to the variant repeat of the circumsporozoite protein of Plasmodium vivax in Peru. Am J Trop Med Hyg 46: 708-710.

González-Ceron L, Rodriguez MH, Nettel JC, Villarreal C, Kain KC, Hernandez JE 1999. Differential susceptibilities of Anopheles albimanus and Anopheles pseudopunctipennis to infections with coindigenous Plasmodium vivax variants VK210 and VK247 in southern Mexico. Infect Immun 67: 410-412.

Gopinath R, Wongsrichanalai C, Cordon-Rosales C, Mirabelli L, Kyle D,Kain KC 1994. Failure to detect a Plasmodium vivax-like malaria parasite in globally collected blood samples. J Infect Dis 170: 16301633.

Kain KC, Keystone J, Franke ED, Lanar DE 1991. Glo- 
bal distribution of a variant of the circumsporozoite gene of Plasmodium vivax. J Infect Dis 164: 208-210.

Mann VH, Huang T, Cheng Q, Saul A 1994. Sequence variation in the circumsporozoite protein gene of Plasmodium vivax appears to be regionally biased. Mol Biochem Parasitol 68: 45-52.

Marrelli MT, Branquinho MS, Hoffmann EH, TaipeLagos CB, Natal D,Kloetzel JK 1998. Correlation between positive serology for Plasmodium vivaxlike/Plasmodium simiovale malaria parasites in the human and anopheline populations in the State of Acre, Brazil. Trans R Soc Trop Med Hyg 92: 149151

Menard R, Sultan AA, Cortes C, Altszuler R, van Dijk MR, Janse CJ, Waters AP, Nussenzweig RS, Nussenzweig V 1997. Circumsporozoite protein is required for development of malaria sporozoites in mosquitoes. Nature 385: 336-340.

Qari SH, Shi YP, Goldman IF, Udhayakumar V, Alpers MP, Collins WE,Lal AA 1993a. Identification of Plasmodium vivax-like human malaria parasite. Lancet 341: 780-783.
Qari SH, Shi YP, Povoa MM, Alpers MP, Deloron P, Murphy GS, Harjosuwarno S,Lal AA 1993b. Global occurrence of Plasmodium vivax-like human malaria parasite. J Infect Dis 168: 1485-1489.

Rosenberg R, Wirtz RA, Lanar DE, Sattabongkot J, Hall T, Waters AP, Prasittisuk C 1989. Circumsporozoite protein heterogeneity in the human malaria parasite Plasmodium vivax. Science 245: 973-976.

Salas ML, Romero JF, Solarte Y, Olano V, Herrera MA, Herrera S 1994. Development of sporogonic cycle of Plasmodium vivax in experimentally infected Anopheles albimanus mosquitoes. Mem Inst Oswaldo Cruz 89: 115-119.

Sattabongkot J, Suwanabun N, Rongnoparut P, Wirtz RA, Kain KC, Rosenberg R 1994. Comparative test of DNA probes for detection of Plasmodium vivax circumsporozoite protein polymorphism VK 247 and VK 210. J Infect Dis 169: 464-466.

Wirtz RA, Rosenberg R, Sattabongkot J, Webster HK 1990. Prevalence of antibody to heterologous circumsporozoite protein of Plasmodium vivax in Thailand. Lancet 336: 593-595. 